\title{
DC traction power substation using eighteen-pulse rectifier transformer system
}

\author{
Chuen Ling Toh ${ }^{1}$, Chee Wei Tan ${ }^{2}$ \\ ${ }^{1}$ Department of Electrical and Electronic Engineering, College of Engineering, Universiti Tenaga Nasional, Malaysia \\ ${ }^{2}$ Division of Electrical Power Engineering, School of Electrical Engineering, Faculty of Engineering, Universiti \\ Teknologi Malaysia, Malaysia
}

\begin{tabular}{l} 
Article Info \\
\hline Article history: \\
Received Jun 29, 2021 \\
Revised Sep 3, 2021 \\
Accepted Sep 10, 2021 \\
\hline
\end{tabular}

\section{Keywords:}

DC traction power substation Harmonic mitigation Multipulse rectifier Phase-shifting transformer Total harmonic distortion

\begin{abstract}
Twelve-pulse rectification system had been widely integrated in today's DC traction power sub-station (DC-TPSS). This configuration had successfully mitigated low order harmonic distortion. As some research findings had confirmed that the DC voltage and current ripple factors may further minimize by increasing the number of rectification pulses to 18,24 , or 36 . This paper had presented a simulation study to investigate the prospect of implementing an eighteen-pulse rectification system in a DC-TPSS. The theory of phase-shifting transformer used to produce an 18-pulse rectifier is presented with simulation verification. Simulation result shows that $3.69 \%$ of grid current distortion index is recorded without installing any filters. In addition, the DC voltage and current ripple may also be further reduced for about $30 \%$ compared to a conventional twelve-pulse rectification system.
\end{abstract}

This is an open access article under the CC BY-SA license.

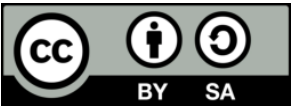

\section{Corresponding Author:}

Chuen Ling Toh

Department of Electrical and Electronic Engineering, College of Engineering

Universiti Tenaga Nasional

Jalan IKRAM-UNITEN, 43000 Kajang, Selangor, Malaysia

Email: chuenling@uniten.edu.my

\section{INTRODUCTION}

Most of the urban metros are powered by standard DC railways voltages rated at $750 \mathrm{~V}$. A typical DC traction power substation is generally consists of a traction transformer and rectifier [1], [2]. The conventional six-pulse rectifier has first been integrated [3] in the substation. Unfortunately, significant harmonics distortion is observed both in ac and DC terminals. As a result, to meet the harmonics requirements [4], bulky and costly passive filters are being installed [5], [6].

With the invention of phase-shifting transformer [7], multipulse rectifier transformer system has started to be used in DC traction power substation. Figure 1 illustrates a twelve-pulse rectifier transformer system which is employed in a DC traction power substation. The main advantage offers by this system is that the low order ac harmonics will be cancelled out automatically. This is mainly cause by the phase angle displacement produced by the phase-shifting transformer. In addition, the DC voltage and current ripples will also be reduced. As a result, the size of passive filters had been reduced drastically. It is highlighted that by increasing the number of pulses in rectification, the quality of voltage and current waveforms will be further improved [8], [9].

Many research findings have denoted that an eighteen-pulse rectifier transformer system may help to further reduce total harmonics distortion (THD) ranging from 2\%-3\% compare to a commonly used 12-pulse system [10]-[12]. Therefore, this paper will present a simulation study of integrating an eighteenpulse rectifier transformer system in Malaysia light-rail-transit (LRT) traction power substation. The main 
objective is to estimate the power quality improvement on ac lines and the ripple factor reduction on DC terminal compared to the existing 12-pulse rectification system. The paper is outlined with presenting the theories of 12-pulse and 18-pulse rectifier transformer systems in Section 2. Section 3 presents simulation analysis for both systems and a conclusion will be summarized in Section 4.

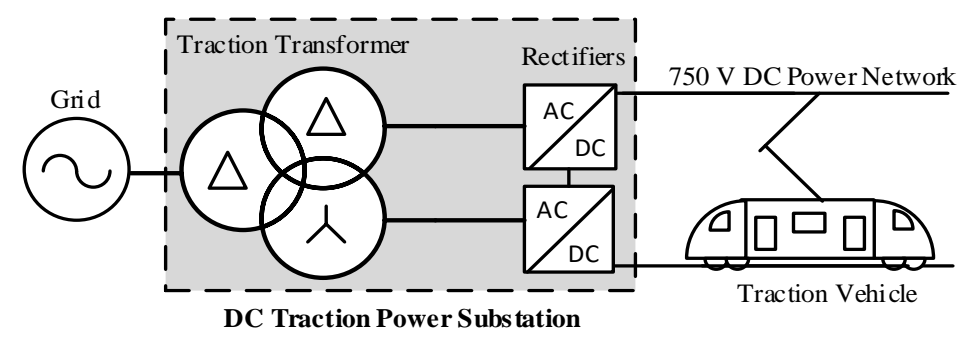

Figure 1. DC Railway Traction Power Substation employing a 12-pulse rectifier transformer system [13]

\section{MULTI-PULSE RECTIFIER TRANSFORMER SYSTEM}

Multipulse rectifier transformer systems have been proposed to enhance the conventional rectification system in various applications. For instance, variable frequency drives [14]-[16], HVDC [17], renewable energy power transmission [18], [19], and aircraft based power supply system [20], [21]. Phaseshifting transformer is the most essential components used to realize 12-pulse, 18-pulse, 24-pulse, or even higher pulses of rectification. Unfortunately, the project cost and circuit complexity will also increase propotionally to the number of pulses [22], [23]. Hence, an 18-pulse rectifier transformer system is investigated for future Malaysia's LRT power substation.

\subsection{Twelve-pulse rectifier transformer system}

The existing 12-pulse rectifier transformer system configured in the traction power substation is presented in Figure 2 (a) [24]. A balance three phase utility supply, $v_{g}$, is assumed to power up the power substation. The three phase voltages can be expressed as:

$$
\begin{gathered}
v_{A}=V_{m} \sin (\omega t) \\
v_{B}=V_{m} \sin \left(\omega t-120^{\circ}\right) \\
v_{C}=V_{m} \sin \left(\omega t+120^{\circ}\right)
\end{gathered}
$$

Where $V_{m}$ is the peak voltage value of the phase voltages and $\omega$ represents the angular frequency of the grid.

A three windings phase-shifting transformer is integrated in between the utility grid and two units of 6-pulse diode rectifiers. These identical rectifiers are connected in parallel. The rectifier power circuit is shown in Figure 2 (b). The delta-connected primary winding of the transformer is configured with $N_{l}$ turns. In order to produce a $30^{\circ}$ phase shifting at its secondary output terminals, two set of coils with $N_{2}$ and $N_{3}$ turns are configured in delta and star connection as shown in Figures 2 (c) and (d). The turn ratio of the transformer can be determined from the effective voltage drop acrossed the coils.

$$
\begin{aligned}
& a_{\Delta \mid \Delta}=\frac{N_{1}}{N_{2}}=\frac{V_{A B}}{V_{a b, s 1}} \\
& a_{\Delta \mid Y}=\frac{N_{1}}{N_{3}}=\frac{V_{A B}}{\sqrt{3} V_{a b, s 2}}
\end{aligned}
$$

The secondary winding 1 voltages, $v_{s}$, are in phase with the grid voltages, $v_{g}$. The secondary winding 2 voltages, $v_{s 2}$, are leading the grid voltages for $30^{\circ}$. As these secondary voltages are applied to the six-pulse rectifiers, $\operatorname{Rec}_{1}$ and $\operatorname{Rec}_{2}$, the AC power will be rectified. Referring to the power circuit, one of the diodes in the top half of the bridge may conduct as its anode terminal is supplied with highest phase voltage. Consequently, one diode in the bottom half bridge will conduct with its cathode terminal is connected to the lowest phase voltage.

\subsection{Eighteen-pulse rectifier transformer}

In this paper, authors propose to use a delta-connected primary phase shifting transformer with the secondary windings configured with angle displacement of $0^{\circ},-20^{\circ}$, and $-40^{\circ}$. This configuration is commonly 
used in motor drives applications [14]. Figure 3 (a) illustrates the proposed system configuration in the traction power substation. Three units of six-pulse diode rectifiers are demanded. As shown in the diagram, rectifiers, $R e c_{1}-R e c_{3}$, will be fed with three set of voltages, $v s_{1}-v s_{3}$, which are displaced by $20^{\circ}$ from each other. All the rectifiers will be connected in parallel like the existing 12-pulse rectifier transformer system.

Each respective connection and phasor diagram of the transformer are presented in Figure 2 (c), Figures 3 (b) and (c). The $0^{\circ}$ phase-shift secondary winding terminal generates voltages, $v_{s l}$. These three phase voltages are in-phase with the grid voltages, $v_{g}$. The turn ratio for this configuration is presented in (2). On the other hand, the zigzag-connected secondary winding 2 and winding 3 have identical set of coils on primary and secondary sides. As shown in Figure 3 (b) $N_{l}$ turns of coils are winded in primary side of the transformer in delta connection. Two set of coils, $N_{4}$, and $N_{5}$ are winded at sencondary side per phase. The $N_{4}$ coils are connected in delta, whereas the $N_{5}$ coil is connected in series with $N_{4}$ coil for each phase. The required phase shifting angles, $-20^{\circ}$, and $-40^{\circ}$ are measured by examining the angle between the primary and secondary line-toline voltages, $V_{A B}$ and $V_{a b, s 2}$ or $V_{a b, s 3}$. Thus, by appropriately setting up the turn ratio of $N_{4}$, and $N_{5}$, the required phase shifting angles can be established. For instance, by evaluating the phasor diagram of Figure 3 (b), the rms voltage across $N_{5}$ coil, $V_{q}$, and the rms phase voltage between nodes $a$ and $u, V_{a u, s 2}$, can be derived using a triangular composed of $V_{q}, V_{b v, s 2}$ and $V_{a b, s 2}$.

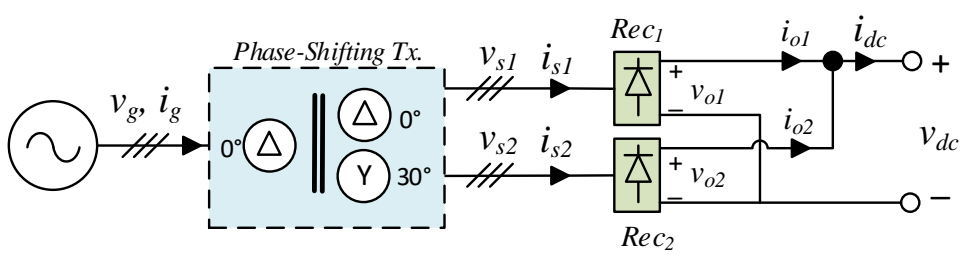

(a)

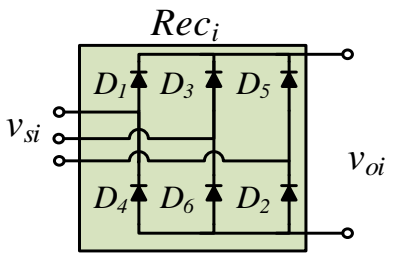

(b)

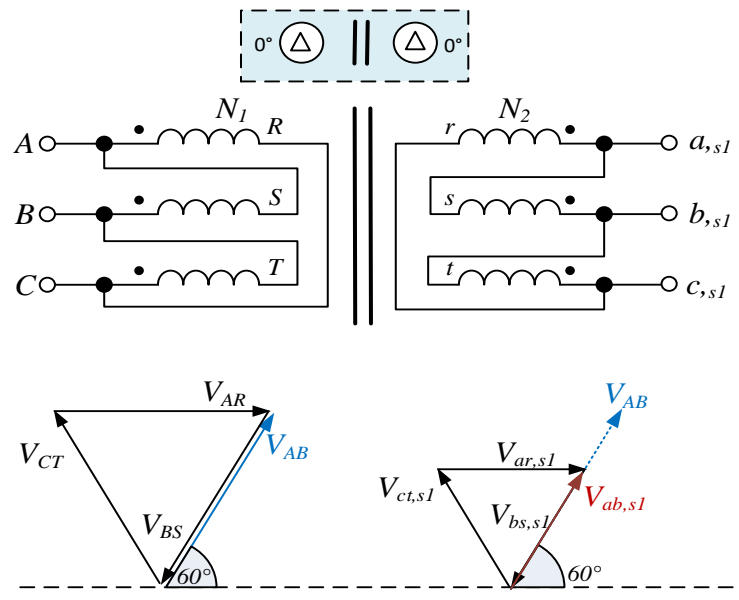

(c)
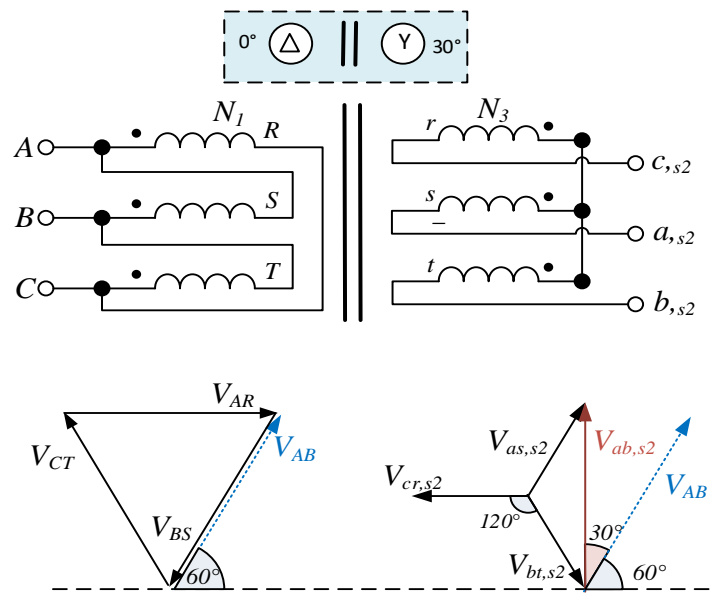

(d)

Figure 2. These figures are; (a) 12-pulse rectifier transformer system, (b) 6-pulse rectifier power circuit, (c) connection and phasor diagram of $\Delta / \Delta\left(0^{\circ}\right),(\mathrm{d})$ connection and phasor diagram of $\Delta / \mathrm{Y}\left(30^{\circ}\right)$

$$
\frac{V_{q}}{\sin 20^{\circ}}=\frac{V_{b v, s 2}}{\sin 40^{\circ}}=\frac{V_{a b, s 2}}{\sin 120^{\circ}}
$$

Since a balance three phase voltages is assumed suppling to the transformer, $V_{b v, s 2}$ is equivalent to $V_{a u, s 2}$. Therefore, the turn ratio of the sendondary windings can be derived as:

$$
\frac{N_{5}}{N_{4}+N_{5}}=\frac{V_{q}}{V_{a u, s 2}}=\frac{\sin 20^{\circ}}{\sin 40^{\circ}}=0.5321
$$

Whereas the turn ratio of the primary and secondary windings can be estimated as: 


$$
a_{\Delta \mid z}=\frac{N_{1}}{N_{4}+N_{5}}=\frac{V_{A U}}{V_{a u, s 2}}=\frac{V_{A B}}{V_{a b, s 2}}\left(\frac{\sin 120^{\circ}}{\sin 40^{\circ}}\right)=1.3473 \frac{V_{A B}}{V_{a b, s 2}}
$$

where, $V_{A U}=V_{A B} \frac{\sin 60^{\circ}}{\sin 60^{\circ}}$ and $V_{b v, s 2}=V_{a u, s 2}=V_{a b, s 2} \frac{\sin 40^{\circ}}{\sin 120^{\circ}}$

To obtain the $-40^{\circ}$ phase shift, the delta connected coils at secondary winding are integrated in a reverse order as shown in Figure 3 (c). With the same derivation steps given in (4)-(6), the identical turn ratio will be determined.

\subsection{AC harmonics distortion}

With the assumption of a balanced grid voltages are supplied to the traction power substation, the output currents of the phase-shifting transformer for each secondary winding, $i_{s i}$, can be summarized as:

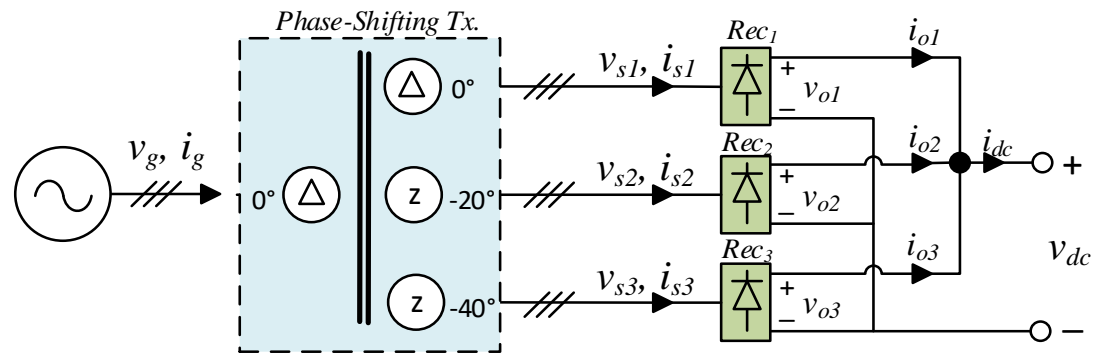

(a)
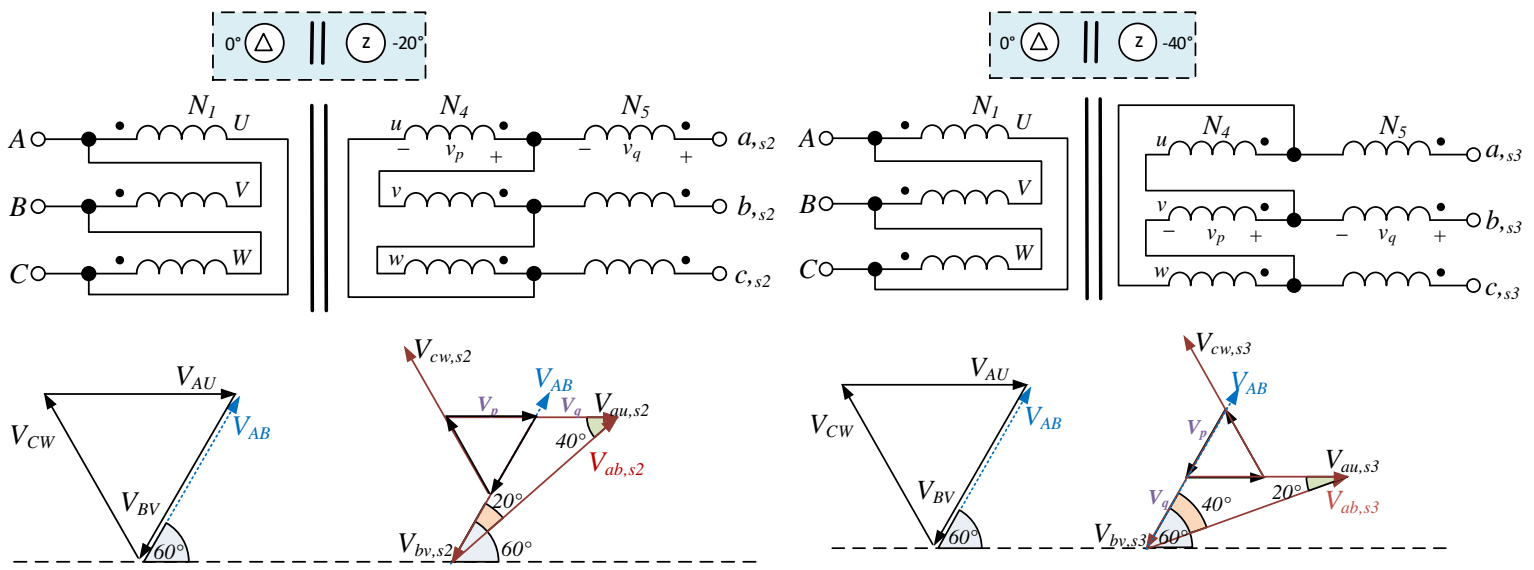

(b)

(c)

Figure 3. These figures are; (a) Eighteen-pulse rectifier transformer system, (b) connection and phasor diagram of $\Delta / Z\left(-20^{\circ}\right)$, (c) connection and phasor diagram of $\Delta / Z\left(-40^{\circ}\right)$

$$
\begin{aligned}
& i_{s i_{a}}=\sum_{n=o d d}^{\infty} I_{m, n} \sin \left(n\left(\omega t+\delta^{\circ}\right)\right) \\
& i_{s i_{b}}=\sum_{n=o d d}^{\infty} I_{m, n} \sin \left(n\left(\omega t-120^{\circ}+\delta^{\circ}\right)\right) \\
& i_{s i_{c}}=\sum_{n=o d d}^{\infty} I_{m, n} \sin \left(n\left(\omega t-240^{\circ}+\delta^{\circ}\right)\right)
\end{aligned}
$$

where $I_{m, n}$ is the peak value of the $n$th order of harmonic current and $\delta$ represents the displacement angle introduced by the phase-shifting transformer. These currents, $i_{s i}$, could be referred to primary side of the transformer, $i_{s i}^{\prime}$, using the general transformer equation as follows:

$$
i_{s i}^{\prime}=\frac{1}{a} i_{s i}
$$


Where $a$ represent the transformer turn ratio. In this paper, this parameter could be substituded by (2), (3), or (6) mainly depends on the primary and secondary windings configuration. Thus, the grid current, $i_{g}$, can be estimated by summing up all referred currents, $i_{s i}^{\prime}$, on the primary windings of the transformer. As shown in (9) and (10) denote idealized phase-a grid current expression for 12-pulse and 18-pulse rectifier transformer system.

$$
\begin{aligned}
& i_{A_{-} 12 p}=i_{s 1}^{\prime}+i_{s 2}^{\prime} \\
& i_{A_{-} 18 p}=i_{s 1}^{\prime}+i_{s 2}^{\prime}+i_{s 3}^{\prime}
\end{aligned}
$$

The details deriavation of harmonic current canellation based on phase displacement of harmonic currents are documented in [14]. Theorectically the grid current harmonics of a $p$-pulse rectifier transformer system should be formularized as:

$$
h_{a c}=p k \pm 1 \text { for } k=1,2,3, \ldots
$$

where $k$ represents an integer. Hence, the most significant harmonics contents for a 12-pulse system should be found in the order of $11^{\text {th }}$ and $13^{\text {th. }}$; whereas an 18-pulse rectifier transformer system will locate at $17^{\text {th }}$ and $19^{\text {th }}$.

As a result, the harmonic distortion is estimated to be minimized using an 18-pulse system based on the Total Harmonic Distortion espression bellows:

$$
T H D_{i}=\frac{\sqrt{\sum_{h_{a c}}^{\infty} I_{h_{a c, r m s}^{2}}}}{I_{1, r m s}} \times 100 \%
$$

Figure 4 shows a set of simulated grid current waveforms for 12-pulse and 18-pulse rectifier transformer systems. The grid currents shown in Figure 4 (a) are more distorted compared to Figure 4 (b).

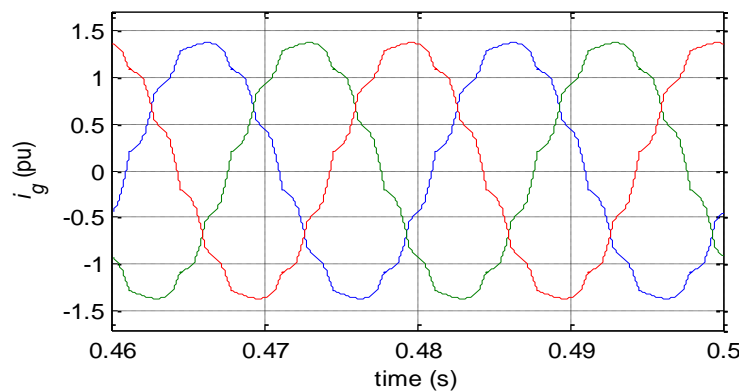

(a)

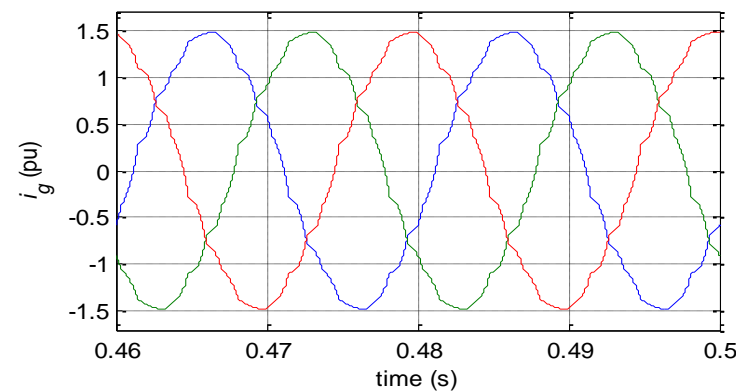

(b)

Figure 4. Grid current waveforms of the rectifier transformer system for, (a) 12-pulse, (b) 18-pulse

\subsection{DC harmonics distortion}

By neglecting the commutation inductance, an ideal output voltage waveform, $v_{D C}$, for a $p$-pulse rectifier transformer system could be sketched (Figure 5). Each rectifier will present a line-line voltage across its DC terminal according to one upper and one lower diode conducted at an instant of time period. Thus, $v_{D C}$, can be expressed as

$$
v_{d c}=\sqrt{2} V_{L L} \cos \omega t \text { for }-\frac{\pi}{p}<\omega t<\frac{\pi}{p}
$$

Where $V_{L L}$ indicates the rms value of the line-line voltages produced by the secondary winding of the transformer. The average output voltage, $V_{D C}$, can be derived as:

$$
V_{d c}=\sqrt{2} V_{L L}\left(\frac{p}{\pi}\right) \sin \frac{\pi}{p}
$$


It is predicted that a 12-pulse and 18-pulse rectifier transformer systems will generate an average output voltage approximate to $1.398 V_{L L}$ and $1.407 V_{L L}$ respectively. The output voltage ripple factor can be formulated as:

$$
\frac{\Delta v_{d c}}{v_{d c}}=\left(\cos 0^{\circ}-\cos \frac{\pi}{p}\right) \times 100 \%
$$

Ideally, about $50 \%$ of voltage ripple reduction will be achieved by replacing the 12-pulse system with an 18pulse system. The DC voltage harmonic contents will exist at multiples of the $p$ pulses as follows:

$$
h_{d c}=p k \text { for } k=1,2,3, \ldots
$$

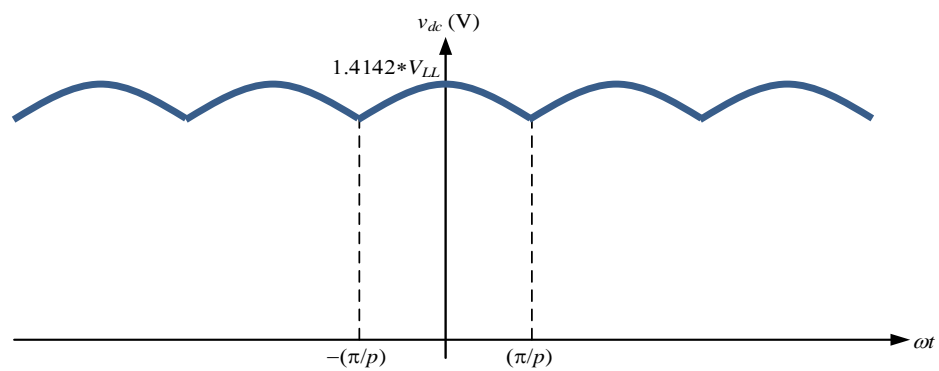

Figure 5. Theoretical output voltage waveform of a $p$-pulse rectifier transformer system [21]

\section{SYSTEM MODELLING AND SIMULATION VERIFICATION}

In order to analyse the power quality of the twelve and eighteen pulses rectifier transformer systems, a DC traction model is built using MATLAB/Simulink as shown in Figure 6 (a). This simulation model is then simulated under rated load condition, using two different set of multipulse rectifier transformer systems (Figures 6 (b), and (c)). Figure 6 (d) shows the power circuit for a 6-pulse rectifier. Three-phase utility grid rated at $33 \mathrm{kV}$ line-to-line voltages are integrated as an input supply for the system. Whereas the LRT traction is model as an $R L$-load based on the field data documented in [24], [25]. Table 1 summarizes all the simulation parameters used in this paper.

Table 1. Parameters of the multipulse rectifier transformer system [24], [25]

\begin{tabular}{ll}
\hline Rated nominal power and frequency of the transformer, $P_{T X}$ and $f$ & \multicolumn{1}{c}{$3.3 \mathrm{MVA}, 50 \mathrm{~Hz}$} \\
\hline Transformer magnetization resistance and inductance & $R_{m}=100 \mathrm{pu}, L_{m}=100 \mathrm{pu}$ \\
Rated nominal line-to-line voltage - primary, $V_{p, r m s}$ & $33 \mathrm{kV}$ \\
Rated nominal line-to-line voltage - secondary, $V_{s, r m s}$ & $585 \mathrm{~V}$ \\
Traction network $R L$-load & $R=187.5 \mathrm{~m} \Omega, L=370 \mu \mathrm{H}$ \\
\hline
\end{tabular}

Figure 7 presents the simulated grid voltages and currents waveforms. The simulation results of 12pulse rectifier transformer system are compiled in column (a) while column (b) reserved for 18-pulse rectifier transformer system. Sub-plot i. show that identical voltage supplies are implemented for both simulations. The three phase voltages are balance with its peak voltage set at $26.94 \mathrm{kV}, 50 \mathrm{~Hz}$. Sub-plot ii. present the simulated three phase grid currents waveforms and sub-plot iii capture the harmonic spectrum of phase-a grid current.

As shown in Figure 7 (a) ii. and iii., a 12-pulse rectifier transformer system draws an effective current of approximately 56.01 A to power up the LRT railway. The Total Harmonic Distortion $\left(T H D_{i}\right)$ are recorded less than 5\%, which fulfilled the IEEE Standard requirement. Its most significant harmonics contents are measured at $11^{\text {th }}, 13^{\text {th }}, 23^{\text {rd }}$, and $25^{\text {th }}$ orders, which fulfilled the theorectical expression given in (11). The grid current waveforms shown in Figure 7 (b) ii. are obviously more sinusoidal compared to the 12pulse system. The effective current drawn by an 18-pulse rectifier transformer system is slightly higher, which is about 59.76 A. The current harmonis distortion is reduced to 3.69\%. However, additional harmonic contents are recorded in the harmonic spectrum at the order of $5^{\text {th }}, 7^{\text {th }}, 11^{\text {th }}$, and $13^{\text {th }}$ (as highlighted in Figure 7 (b) iii.). This simulation result does not comply with the theorectical formulation of ac harmonics equation. Therefore, further investigation is conducted by examining the 18-pulse phase-shifting transformer secondary windings. 
Phase-a current waveforms for each secondary winding are compiled in Figure 8. Figure 8 (a) illustrates current waveform of the delta connected secondary winding, $i_{s l}$. Since the secondary winding is in phase with primary winding of the transformer, a typical 6-pulse rectifier ( $R L$-load) source current waveform is obtained. The effective current of this simulated waveform is calculated as $1154.0 \mathrm{~A}$ with its $T H D_{i}$ is captured at $31.27 \%$. This current waveform contains odd harmonics except tripplen harmonic orders which complies to the theorectical 6-pulse rectification system. The most significant harmonic located at $250 \mathrm{~Hz}$ ( $5^{\text {th }}$ order) with an amplitude of approximately $30 \%$ of its fundamental component. Figure 8 (b) shows the secondary winding ac current waveform of the zigzag transformer set with $-20^{\circ}$ phase displacement, $i_{s 2}$. This current waveform is badly distorted, which contains odd number of harmonic components. The measured $T H D_{i}$ is noted at $93.88 \%$. The effective current of $i_{s 2}$ is computed as $804.4 \mathrm{~A}$. Lastly, Figure 8 (c) depitches another zigzag transformer current waveform with the displacement angle set to $-40^{\circ}, i_{s 3}$. The rms current and $T H D_{i}$ of $i_{s 3}$ is simulated as $1703 \mathrm{~A}$ and $30.88 \%$.

In summary, those additional harmonic contents of the grid current (as highlighted in Figure 7 (b) iii.) are resulted from the badly distorted current waveforms produced in the zigzag transformers. The displacement angles, $-20^{\circ}$ and $-40^{\circ}$, selected for the phase-shifting transformer in this paper fails to achieve the harmonic cancellation theory [14].

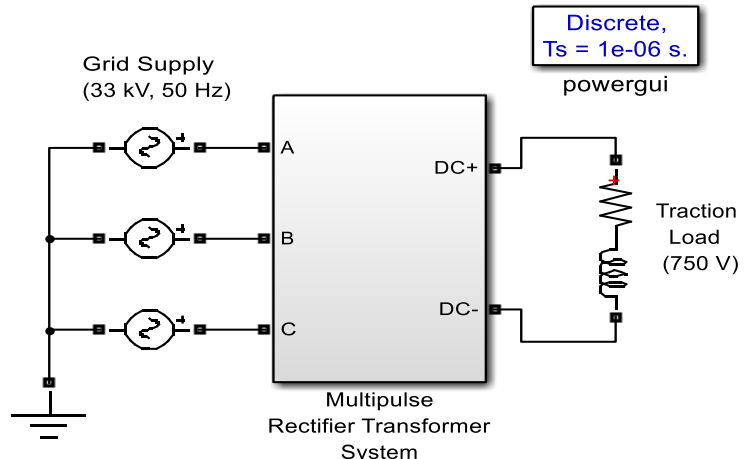

(a)

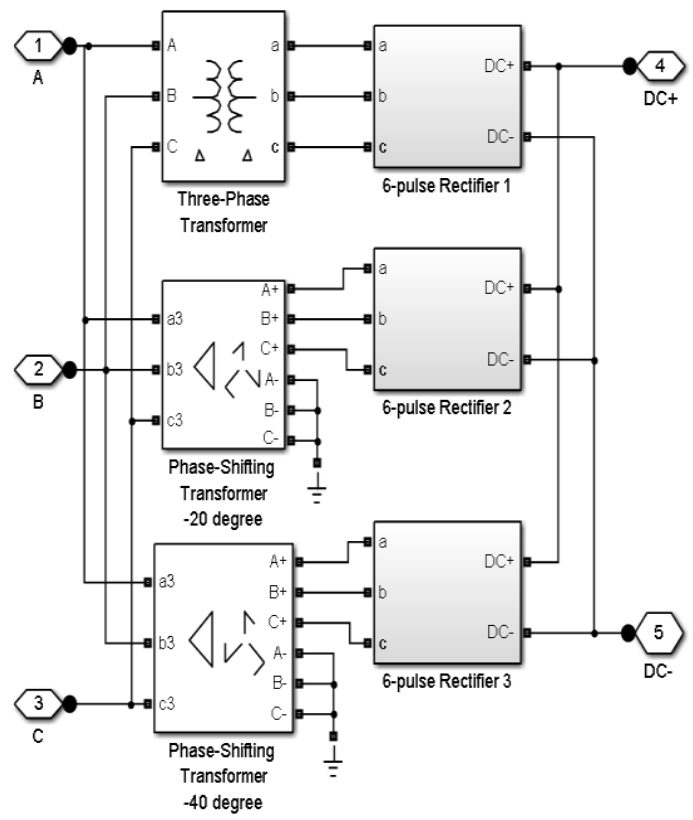

(d)

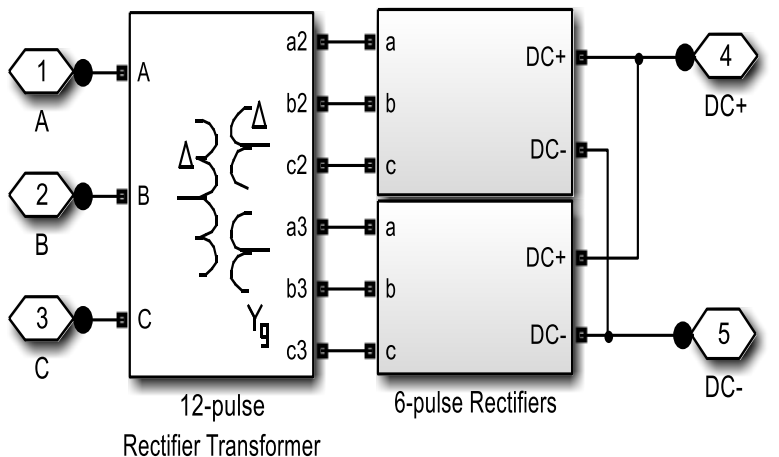

(b)

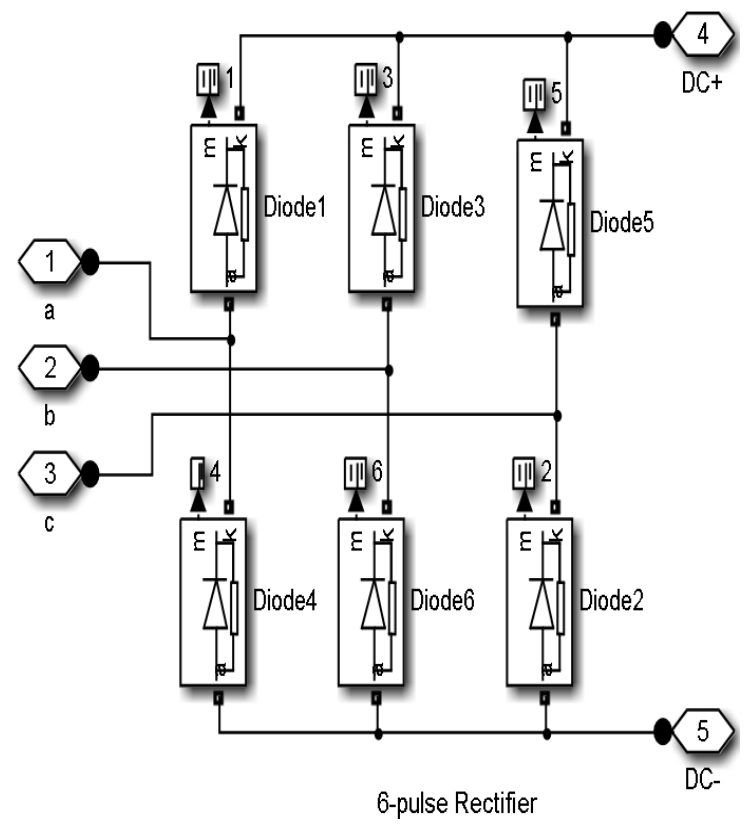

(d)

Figure 6. These figures are; (a) Simulation model of multipulse rectifier transformer, (b) 12-pulse rectifier transformer configuration with $\Delta / \Delta\left(0^{\circ}\right)$ and $\Delta / \mathrm{Y}\left(30^{\circ}\right)$, (c) 18-pulse rectifier transformer configuration with $\Delta / \Delta\left(0^{\circ}\right), \Delta / Z\left(-20^{\circ}\right)$ and $\Delta / Z\left(-40^{\circ}\right),(\mathrm{d})$ power circuit of 6-pulse rectifier 

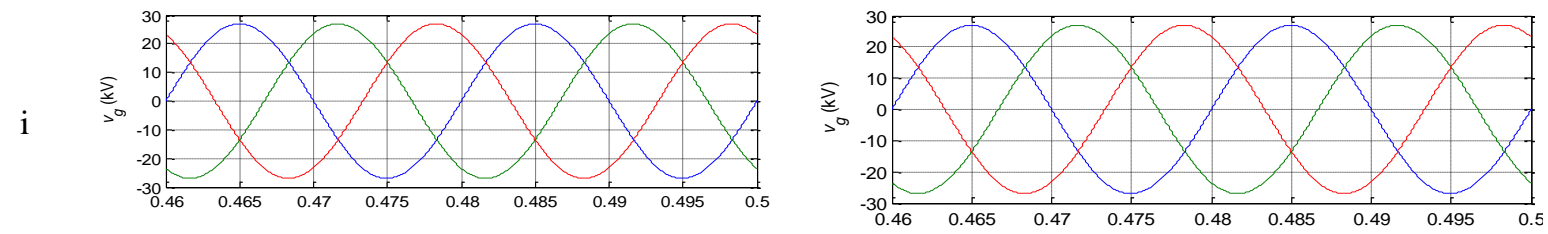

ii
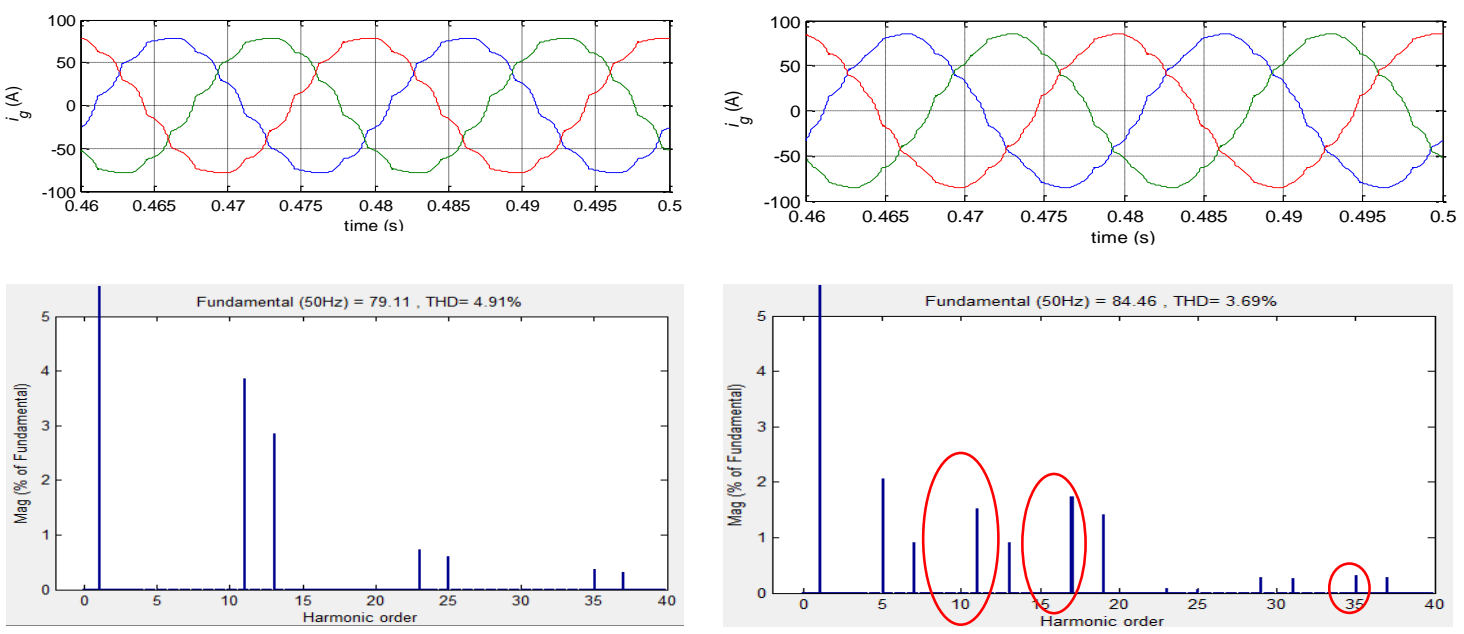

(a)

(b)

Figure 7. Simulation results for rectifier transformer (a) 12-pulse; (b) 18-pulse. The sub-plots show: i. Phase voltage waveforms, ii. Line current waveforms, iii. Harmonic spectrum of phase-a line current waveform

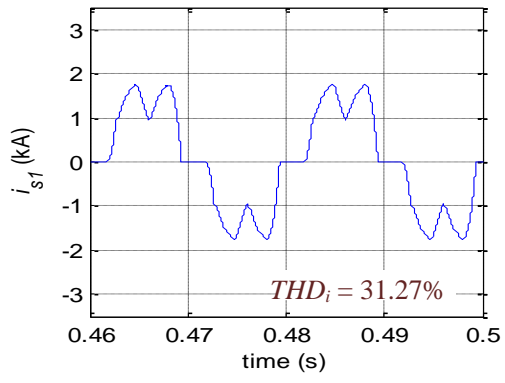

(a)

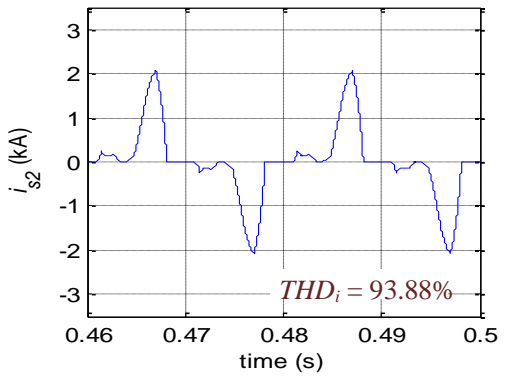

(b)

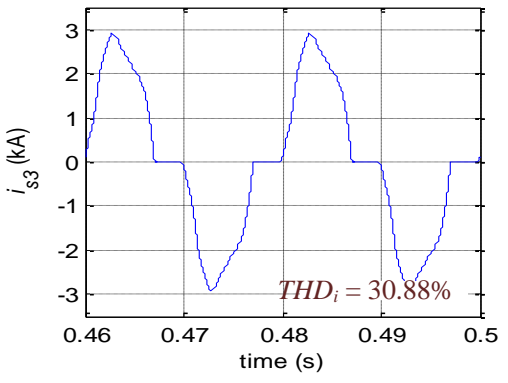

(c)

Figure 8. Phase-a secondary winding current waveform of 18-pulse rectifier transformer system: (a) $i_{s 1}\left[\Delta / \Delta\left(0^{\circ}\right)\right]$, (b) $i_{s 2}\left[\Delta / \mathrm{Z}\left(-20^{\circ}\right)\right]$, and (c) $i_{s 3}\left[\Delta / \mathrm{Z}\left(-40^{\circ}\right)\right]$

In Figure 9 shows the rectified DC voltages and current waveforms for both rectifier transformer systems. The simulation results prove that 18-pulse rectifier system offers better DC voltage and current quality compared to the 12-pulse system. The FFT results presented in Figure 10 (a) shows that the average DC voltages are computed as $744.2 \mathrm{~V}$ and $758.6 \mathrm{~V}$ for 12 -pulse and 18-pulse systems. As compare, the voltage ripples have been further reduced for $20 \mathrm{~V}$ with the application of 18-pulse rectifier system. On the other hand, the DC current shows an increment of about $77 \mathrm{~A}$. Besides, the current ripple is also further minimized for about $13 \mathrm{~A}$. Both current and voltage ripple factors do not achieve $50 \%$ reduction mainly due to this simulation taking into accout the inductive load for analysis. The DC voltage and current harmonics contents for the 12-pulse rectification system is found at $12^{\text {th }}, 24^{\text {th }}$, and $36^{\text {th }}$ orders following the theorectical formulation. Unfortunately, the 18-pulse system DC voltage and current harmonics exist in order of sixmultiplication. These additional harmonic contents as highlighted in Figure 10 (b) are mainly affected by highly distorted secondary transformers currents, $i_{s 2}$, and $i_{s 3}$. 

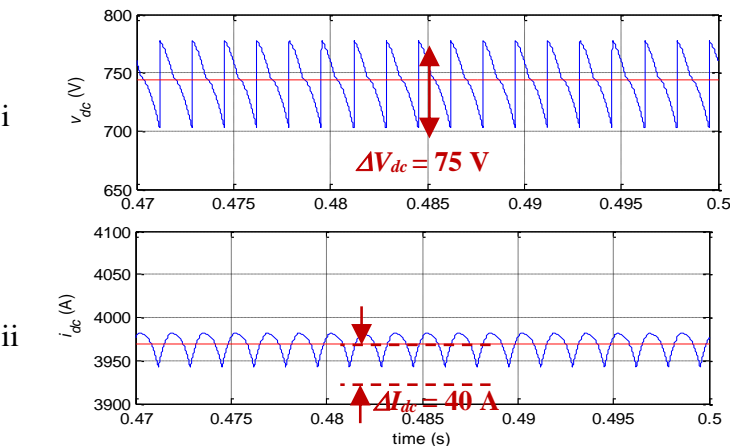

(a)

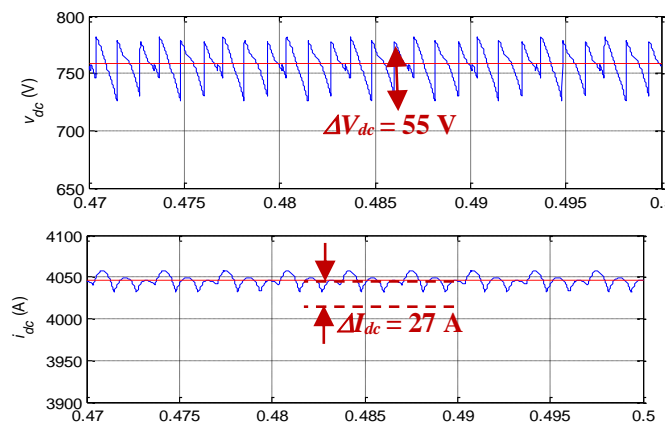

(b)

Figure 9. Simulation results for, (a) 12-pulse transformer rectifier, (b) 18-pulse transformer rectifier. The subplots show: i. DC voltage waveform, ii. DC current waveform.
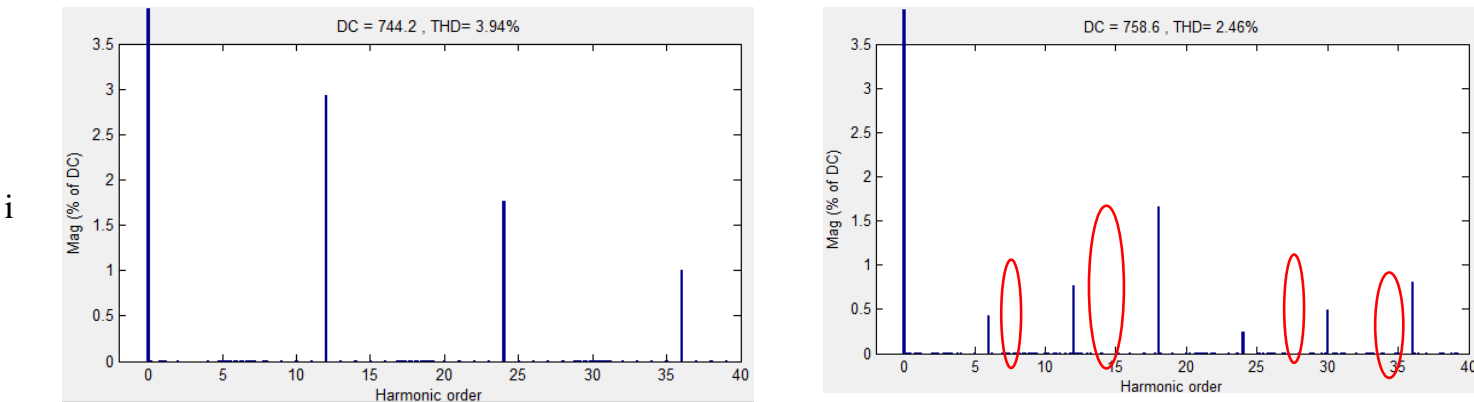

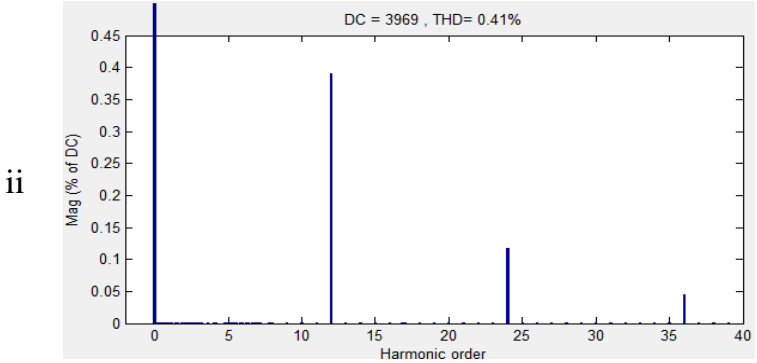

(a)

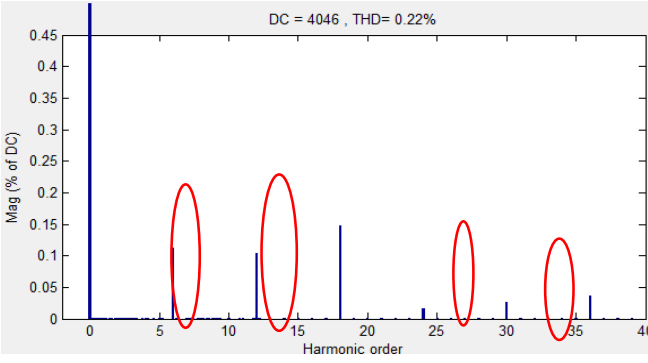

(b)

Figure 10. Simulation results for, (a) 12-pulse transformer rectifier, (b) 18-pulse transformer rectifier. The sub-plots show harmonic spectrum for: i. DC voltage waveform, ii. DC current waveform

\section{CONCLUSION}

The potential of implement an 18-pulse rectifier transformer in LRT traction power substation has been investigated. This paper had proposed to use a phase-shifting transformer which had been widely used in motor drive applications. The primary winding of the transformer is configured in delta connection, whereas the secondary winding of the transformer is winded in delta and zigzag configurations to form respective displacement angles of $0^{\circ},-20^{\circ},-40^{\circ}$. The fundamental concept of 12-pulse and 18-pulse phase-shifting transformer had been presented in detail with ac and DC harmonics formulation. The proposed system had been modelled and simulated to evaluate its feasibility. The simulation results prove that further mitigation of about $1.22 \%$ ac current harmonic distortion had been achieved. In addition, the DC voltage and current ripple may also be further reduced for about $30 \%$. However, the harmonics contents for the proposed 18-pulse rectifier transformer does not match with the theorectical formulation. It is found that those additional harmonics orders mainly contributed by the zigzag secondary windings of the phase-shifting transformer. 


\section{ACKNOWLEDGEMENTS}

The authors are pleased to express their appreciation to the Universiti Tenaga Nasional for sponsoring the BOLD Research Grant 2020 (BOLD 2020) and BOLD Refresh 2025 to conduct this research. Project Code: RJO10517844/085.

\section{REFERENCES}

[1] R. J. Hill, "Electric railway traction. Part 3. Traction power supplies," in Power Engineering Journal, vol. 8, no. 6, pp. 275-286, Dec. 1994, doi: 10.1049/pe:19940604.

[2] G. Abad, "Power electronics and electric drives for traction applications," John Wiley \& Sons. Ltd., pp. 221-361, 2017.

[3] R. D. White, "AC/DC railway electrification and protection," 2008 IET Professional Development course on Electric Traction Systems, 2008, pp. 258-305, doi: 10.1049/ic:20080517.

[4] "IEEE Recommended Practice and Requirements for Harmonic Control in Electric Power Systems," in IEEE Std 519-2014 (Revision of IEEE Std 519-1992), vol., no., pp.1-29, 11 June 2014, doi: 10.1109/IEEESTD.2014.6826459.

[5] T. Shudarek, "Harmonic mitigation in variable frequency drives: 6-pulse drives with harmonic filter vs. 18-pulse drive," MTE Corporation, pp. 1-9, 2012.

[6] M. Aeberhard, C. Courtois and P. Ladoux, "Railway traction power supply from the state of the art to future trends," SPEEDAM 2010, 2010, pp. 1350-1355, doi: 10.1109/SPEEDAM.2010.5542093.

[7] "IEEE Guide for the Application, Specification, and Testing of Phase-Shifting Transformers," in IEEE Std C57.135-2011 (Revision of IEEE Std C57.135-2001), vol., no., pp.1-50, 19 Aug. 2011, doi: 10.1109/IEEESTD.2011.5993462.

[8] L. Gao, X. Xu, Z. Man and J. Lee, "A 36-Pulse Diode-Bridge Rectifier Using Dual Passive Harmonic Reduction Methods at DC Link,” in IEEE Transactions on Power Electronics, vol. 34, no. 2, pp. 1216-1226, Feb. 2019, doi: 10.1109/TPEL.2018.2835511.

[9] Y. Li, K. Xu, Y. Lian, W. Yang and S. Yang, "A novel 36-pulse rectifier with a low loss interphase converter at DC side," 2017 IEEE Transportation Electrification Conference and Expo, Asia-Pacific (ITEC Asia-Pacific), 2017, pp. 1-6, doi: 10.1109/ITEC-AP.2017.8080878.

[10] Y. Zhang, Z. Chen, B. Li and Y. He, "Application of Low Harmonic 18-Pulse Rectifier Power Supply for Radar Power System," in IEEE Transactions on Industrial Electronics, vol. 66, no. 2, pp. 1080-1088, Feb. 2019, doi: 10.1109/TIE.2018.2831188.

[11] Q. Li, F. Meng and H. Zhang, "A Series-connected 18-pulse Rectifier Using Isolated Transformer," 2019 22nd International Conference on Electrical Machines and Systems (ICEMS), 2019, pp. 1-5, doi: 10.1109/ICEMS.2019.8922339.

[12] E. Sokol, V. Zamaruiev, V. Ivakhno, Y. Voitovych, O. Butova and V. Makarov, "18-Pulse Rectifier with Electronic Phase Shifting and Pulse Width Modulation," 2018 IEEE 3rd International Conference on Intelligent Energy and Power Systems (IEPS), 2018, pp. 290-294, doi: 10.1109/IEPS.2018.8559530.

[13] A. Awalludin and C. L. Toh," "Harmonic Mitigation in Traction Supply Substation using Cascaded H-Bridge Converter," International Journal of Power Electronics and Drive Systems, vol. 9, no. 4, pp. 1745-1754, 2018, doi: 10.11591/ijpeds.v9.i4.pp1745-1754.

[14] Bin Wu and M. Narimani, "Hign-power converters and AC drives," John Wiley \& Sons, pp. 37-94, 2017.

[15] B. Singh, G. Bhuvaneswari and V. Garg, "A Novel Polygon Based 18-Pulse AC-DC Converter for Vector Controlled Induction Motor Drives," in IEEE Transactions on Power Electronics, vol. 22, no. 2, pp. 488-497, March 2007, doi: 10.1109/TPEL.2006.889903.

[16] Z. Cheng and B. Wu, "Dual 18-pulse rectifier for high-power multilevel inverters," 31st Annual Conference of IEEE Industrial Electronics Society, 2005. IECON 2005, 2005, pp. 6 pp.-, doi: 10.1109/IECON.2005.1568960.

[17] D. L. Mon-Nzongo, P. G. Ipoum-Ngome, T. Jin and J. Song-Manguelle, "An Improved Topology for Multipulse AC/DC Converters Within HVDC and VFD Systems: Operation in Degraded Modes," in IEEE Transactions on Industrial Electronics, vol. 65, no. 5, pp. 3646-3656, May 2018, doi: 10.1109/TIE.2017.2762646.

[18] F. Cheng, L. Yao, K. Ji, C. Ding, Q. Wang and J. Deng, "Enhanced Diode-rectifier HVDC for Offshore Wind Power Transmission," 2019 4th IEEE Workshop on the Electronic Grid (eGRID), 2019, pp. 1-7, doi: 10.1109/eGRID48402.2019.9092657.

[19] Y. Voitovych, V. Makarov and I. Pichkalov, "18-pulse Rectifier with Electronic Phase Shifting with Autotransformer in Inverter and Rectifier Mode," 2018 IEEE 6th Workshop on Advances in Information, Electronic and Electrical Engineering (AIEEE), 2018, pp. 1-5, doi: 10.1109/AIEEE.2018.8592446.

[20] Y. Zhang et al., "Modeling and Prediction of the Reliability Analysis of an 18-Pulse Rectifier Power Supply for Aircraft Based Applications," in IEEE Access, vol. 8, pp. 47063-47071, 2020, doi: 10.1109/ACCESS.2020.2977197.

[21] S. Li, D. Wang, C. Li and Y. Zhang, "The Steady State Limits Application of 18-pulse Rectifier in Aircraft Radar Power Supply System,” 2021 6th Asia Conference on Power and Electrical Engineering (ACPEE), 2021, pp. 14511455, doi: 10.1109/ACPEE51499.2021.9436992.

[22] B. J. McRee, D. A. Dodson, D. A. Wetz, I. J. Cohen, J. M. Heinzel and Q. Dong, "Investigation of harmonic distortion in multi-pulse rectifiers for large capacitive charging applications," 2016 IEEE International Power Modulator and High Voltage Conference (IPMHVC), 2016, pp. 404-408, doi: 10.1109/IPMHVC.2016.8012817. 
[23] A. Panchbhai, Y. R. Patel and N. Prajapati, "Simulation and hardware of multi-pulse rectifier for more electric aircraft," 2016 IEEE 7th Power India International Conference (PIICON), 2016, pp. 1-6, doi: 10.1109/POWERI.2016.8077161.

[24] M. Rajaratnam, P. Guyard, N. Mazet, "Plan of Instruction - Traction Power Sub-Station (TPSS) Overall System Description," Konsortium CMC-COLAS-UNIWAY, Kuala Lumpur, 2016.

[25] T. Z. Y. Chua, Y. T. Ong and C. L. Toh, "Transformerless DC traction power conversion system design for lightrail-transit (LRT)," 2017 IEEE Conference on Energy Conversion (CENCON), 2017, pp. 38-43, doi: 10.1109/CENCON.2017.8262454.

\section{BIOGRAPHIES OF AUTHORS}

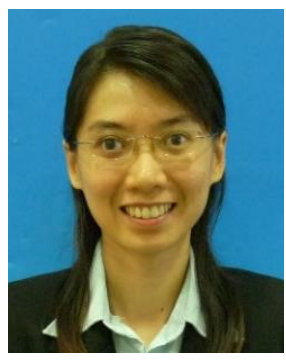

Chuen Ling Toh received the B. Eng. and M. Eng. degree in electrical engineering, both from Universiti Teknologi Malaysia (UTM), Skudai, Malaysia, in 2002 and 2005 respectively; and her $\mathrm{Ph} . \mathrm{D}$ in Electrical Power Engineering from Norwegian University of Science and Technology (NTNU), Trondheim, Norway, in 2014. Currently, she is a Senior Lecturer at the Universiti Tenaga Nasional, Kajang, Malaysia. Her teaching and research interests include the field of power electronics, motor drive systems and field programmable gate array applications. She is also an engineer registered with Board of Engineers Malaysia and a professional technologist registered with Malaysia Board of Technologists.

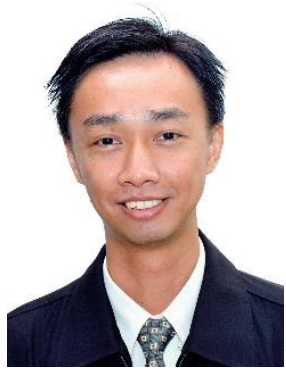

Chee Wei Tan received his B.Eng. degree in Electrical Engineering (First Class Honors) from Universiti Teknologi Malaysia (UTM), in 2003 and a Ph.D. degree in Electrical Engineering from Imperial College London, London, U.K., in 2008. He is currently an associate professor at Universiti Teknologi Malaysia and a member of the Power Electronics and Drives Research Group, School of Electrical Engineering, Faculty of Engineering. His research interests include the application of power electronics in renewable/alternative energy systems, control of power electronics and energy management system in microgrids. He is also a Chartered Engineer registered with Engineering Council, UK, a professional engineer registered with Board of Engineers Malaysia and a professional technologist registered with Malaysia Board of Technologists. He is actively participating in IEEE activities and conferences, which he is also the chair of the IEEE Power Electronic Society (PELS) Malaysia Chapter for year 2018. He was awarded the Malaysia Research Star Award (High Impact Paper - Engineering and Technologies) 2018 by the Ministry of Education Malaysia. 